\title{
Contaminación Bacteriana del Aerosol Dental con y sin Uso de una Cúpula de Acrílico en un Paciente en Pandemia COVID-19
}

\author{
Bacterial Contamination of Dental Aerosol with and Without \\ Use of an Acrylic Dome in a Patient in COVID-19 Pandemic
}

María Cecilia Venegas Arques; Carolina Pia Rojas García²; Yuri Andrés Cataldo Saavedra; Paula Fernanda Jiménez Gomez ${ }^{4}$; Victoria Inés Arqués Vergara ${ }^{5}$ \& Benjamín Martinez ${ }^{6}$

\begin{abstract}
VENEGAS, A. M. C.; ROJAS, G. C. P.; CATALDO, S. Y. A.; JIMÉNEZ, G. P. F.; ARQUÉS, V. V. I. \& MARTINEZ, B. Contaminación bacteriana del aerosol dental con y sin uso de una cúpula de acrílico en un paciente en pandemia COVID-19. Int. J. Odontostomat., 15(1):14-22, 2021

RESUMEN: En la actual pandemia por COVID-19, el mundo clínico se ha visto obligado a reforzar el uso de protección en el quehacer asistencial, debido al alto grado de contagio y virulencia de este virus. En odontología, debido a la producción de aerosoles, se han suspendido las atenciones clínicas para prevenir contagios. El objetivo de esta investigación es determinar la cantidad de contaminación bacteriana, generada por el uso de aerosol con micromotor de alta velocidad, realizado por dentistas del Hospital de La Florida, Santiago de Chile. El estudio contó con 10 pacientes por box, con 2 muestras por paciente, en total 40 placas de cultivo, 20 Control, 20 Prueba y 3 Ambientales. El medio de cultivo se mantuvo por 10 minutos, ubicado en la frente del operador y pechera del paciente, se realizó simulación de operatoria con turbina, sin aislamiento absoluto, con y sin uso de una cúpula de acrílico, puesta en un paciente sano. Las muestras fueron analizadas macroscópicamente, incubadas a $37^{\circ} \mathrm{C}$ en una atmósfera de oxígeno por 24 horas y dióxido de Carbono a las 48 horas. 43 placas fueron positivas, observándose, en las muestras de la pechera una diferencia no significativa $(p=0,753$ ) entre ambos grupos, con una diferencia promedio de 56,76 UFC. En las placas de la frente del operador, un promedio de 8.1 UFC en Box sin cúpula y 3,9 UFC en el box con cúpula, encontrándose diferencia estadísticamente significativa ( $p=0,0391)$. Las placas ambientales 28,33 UFC en el Box con cúpula, 29 UFC en el Box control y Box sin cúpula 46,66 UFC. Al comprobar que la cúpula de acrílico contiene eficazmente los aerosoles, corresponde utilizarlo como norma de bioseguridad para proteger tanto al equipo dental, como a los pacientes en tiempos de pandemia contra el COVID-19.
\end{abstract}

PALABRAS CLAVE: aerosoles, covid-19, pandemia, humanos, hospitales, dentistas.

\section{INTRODUCCIÓN}

Desde principios de diciembre 2019, en Wuhan, provincia de Hubei, China, se han reportado casos de neumonía de etiología desconocida, los cuales rápidamente evolucionaron a síndrome de dificultad respiratoria aguda (SARS), insuficiencia respiratoria aguda y otras complicaciones graves.

El 7 de enero, el Centro Chino para el Control y la Prevención de Enfermedades (CDC) identificó la causa como un nuevo coronavirus de la muestra de hisopo de la garganta de un paciente, siendo denominada por la Organización Mundial de la Salud como CoV-2019 (Chen et al., 2020; Yi et al., 2020).

El 30 de enero 2020 la OMS declara al Coronavirus SARS CoV-2, que causa la enfermedad COVID-19 una emergencia de salud pública de preocupación internacional, siendo declarada

\footnotetext{
${ }^{1}$ Odontóloga- Ortodoncista de CAIF Hospital de la Florida Eloísa Diaz, Santiago de Chile.

2 Odontóloga- Cirujano Maxilofacial del Hospital de la Florida Eloísa Diaz, Santiago de Chile.

${ }^{3}$ Odontólogo- Rehabilitador Oral del Hospital de la Florida Eloísa Diaz, Santiago de Chile.

${ }^{4}$ Odontólogo- Implantólogo del Hospital de la Florida Eloísa Diaz, Santiago de Chile.

${ }^{5}$ Enfermera retirada del Servicio Metropolitano Sur Oriente, Santiago de Chile.

${ }^{6}$ Odontólogo-Patólogo de la Universidad Mayor, Santiago de Chile.

Este estudio ha sido Patrocinado por el Comité ético Científico del Servicio Metropolitano Sur Oriente, y por Hospital de La Florida, Santiago, Chile.
}

Recibido: 2020-09-07 Aceptado: 2020-09-25 
VENEGAS, A. M. C.; ROJAS, G. C. P.; CATALDO, S. Y. A.; JIMÉNEZ, G. P. F.; ARQUÉS, V. V. I. \& MARTINEZ, B. Contaminación bacteriana del aerosol dental con y sin uso de una cúpula de acrílico en un paciente en pandemia COVID-19. Int. J. Odontostomat., 15(1):14-22, 2021

pandemia el 11 de marzo de 2020 (Ministerio de Salud, 2020).

En Chile el primer caso se presentó el 3 de marzo de 2020 y al 16 de julio se reportaba un total de 323.698 casos confirmados y 7.190 personas fallecidas (Subsecretaría de Salud Pública, 2020). El centro de ciencias de sistemas e ingeniería de la Universidad John Hopkins confirma, a la fecha 10 millones de casos confirmados a nivel mundial y ya superaron los 500.00 muertes en todo el mundo (Johns Hopkins University of Medicine, 2020).

La manifestación de la enfermedad es variada, desde casos asintomáticos, a presencia de fiebre antes y durante de la hospitalización, tos, hallazgos imagenológicos anormales en sistema respiratorio, marcada linfocitopenia y requerimientos de cuidados en unidades de paciente crítico. La mayor morbilidad y mortalidad afecta principalmente a pacientes de la quinta y sexta década, con comorbilidad como diabetes, enfermedad pulmonar crónica, hipertensión, antecedentes cardiovasculares, obesidad y cáncer.

No existe aún vacuna ni tratamiento específico para esta la enfermedad (Chen et al. ; Guan et al., 2020).

Actualmente sabemos que el virus se transmite por vía directa a través de contacto con secreciones y gotitas respiratorias expulsadas desde individuos enfermos o infectados asintomáticos, siendo la carga viral de ambos similares.

Las vías de expulsión del virus por vía directa son a través de la boca y nariz al toser, hablar o estornudar y por vía indirecta mediante el contacto de las manos con superficies contaminadas, con secreciones que se llevan a la mucosa de nariz, ojos y cavidad oral.

Toda persona en contacto cercano (dentro de un metro) con alguien con síntomas respiratorio está en riesgo de exponerse a infección por SARS CoV-2 (Zou et al., 2020).

El período de incubación es de 6,4 días, estableciéndose un promedio de 2 a 14 días (Backer et al., 2020).

Los odontólogos están expuestos a diversos microorganismos y virus provenientes de secreciones de la cavidad bucal, sangre y secreciones respirato- rias por la producción de aerosoles que generan nuestros elementos de trabajo en la cavidad oral. Los procedimientos odontológicos comunes tales como preparaciones dentarias, el uso de ultrasonido y de jeringa triple producen aerosoles y gotitas que representa un riesgo potencial para el médico, el personal dental y el paciente inmunocomprometido.

La American Dental Asociation (ADA) establece como aceptado que al menos 200 unidades formadoras de colonia UFC/ml en el agua de bacterias aerobias de la turbina (Dreyer \& Hauman, 2001). Bustamante et al. (2014), ya registraron que el recuento promedio encontrado en su estudio fue de 58,874 unidades formadoras de colonia UFC por sujeto de estudio.

Es importante destacar que el tamaño de las bacterias es hasta 100 veces más grandes que los virus. Y eso, teniendo en cuenta que en ambos casos son imperceptibles al ojo humano, y sólo se detectan a través de un microscopio especial. Las bacterias pueden verse con un microscopio óptico, mientras que los virus sólo pueden detectarse mediante un microscopio electrónico, empleando una lente electromagnética.

En el caso del virus SARS-CoV-2, aquellas partículas virales que se aerosolizan permanecen en el ambiente por al menos 3 horas, además de permanecer en superficies por hasta 72 horas, siendo alta la estabilidad del virus en elementos de plástico y acero inoxidable (Veena et al., 2015; Van Bushmaker et al., 2020; Subsecretaría de Salud Pública, 2020).

Por lo anterior, es que resulta primordial aumentar las barreras de seguridad de dentistas y pacientes, tanto mediante los elementos de protección personal (EPP) como de barreras adicionales, como el uso de cúpulas de acrílico sobre el paciente que disminuyan la cantidad de aerosol ambiental.

En los procedimientos odontológicos el uso de instrumental rotatorio y jeringa triple crea un spray visible o aerosol, que contiene principalmente gotas de agua, saliva, sangre, microorganismos y otros desechos (Harre \& Molinar, 2004; Hauman,1993). Estos aerosoles precipitan por la gravedad quedando en las superficies, y las partículas pequeñas o microgotas quedan suspendidas en el aire por varias horas, constituyendo un riesgo, ya que pueden ser inhaladas (Shpuntoff \& Shpuntoff, 1993).

Algunos estudios han demostrado que el aerosol generado por el uso de la turbina dentro de la cavi- 
VENEGAS, A. M. C.; ROJAS, G. C. P.; CATALDO, S. Y. A.; JIMÉNEZ, G. P. F.; ARQUÉS, V. V. I. \& MARTINEZ, B. Contaminación bacteriana del aerosol dental con y sin uso de una cúpula de acrílico en un paciente en pandemia COVID-19. Int. J. Odontostomat., 15(1):14-22, 2021

dad bucal emite cerca de 1.000 unidades formadoras de colonias bacterianas, otros han reportado que los microorganismos se han encontrado a $1,80 \mathrm{~m}$ de la turbina en uso (Santiago et al., 1994). Las concentraciones más altas de microorganismos se encontraron a $60 \mathrm{~cm}$ frente al paciente. Se ha reportado que las bacterias generadas por el uso del limpiador ultrasónico (scaler) pueden permanecer en el aire por 24 horas (Pankhurst, 2003).

Por otro lado, está demostrado que los aerosoles contaminados se mantienen en el ambiente entre 30 min y 2 horas y que el SARS-Cov- 2 sobrevive hasta 3 horas en ambientes cargados de aerosoles como es el del box dental. Contaminando, al depositarse, entre 3,5 y 4,5 metros en los boxes dentales Dutil et al., 2009). Se ha detectado el SARS-CoV-2 en muestras de saliva en pacientes sin fiebre y con carga viral alta desde los primeros días después de la infección.

Considerando lo anteriormente expuesto, es que nace la real preocupación de que este aerosol quede en contacto con el equipo de dental, funcionarios, ropa, superficies, suelo, y pueda llegar a los pacientes que acudan a atenderse en el recinto dental, permitiendo una infección por Covid-19 en un huésped susceptible.

Actualmente se cuenta con los EPP (Elementos de Protección Personal) en dental, que son para evitar contagiarse con el virus, sin embargo, no hay evidencia clara de los elementos de protección adicional para el paciente que acude a atenderse. Se está utilizando antiparras para la protección ocular, se realiza enjuague de Peróxido de Hidrógeno con agua en proporción 3:1 por 1 minuto para bajar la carga bacteriana y eventualmente viral, sin embargo, protección para el aerosol que se produce en el procedimiento dental hacia el medio, no se utiliza.

El propósito de esta investigación es determinar la contaminación bacteriana reflejada en Unidad Formadora de Colonias, generada por aerosoles producidos durante una simulación de un procedimiento odontológico, realizada por dentistas de la unidad de dental del Hospital de La Florida, con uso de turbina de alta velocidad, sin aislamiento, con y sin uso de una cúpula de acrílico, puesta en 10 pacientes sanos, funcionarios voluntarios de dental y poder demostrar la efectividad de contención de las bacterias por la cúpula, y con ello disminuir el riesgo de contagio, si lo extrapolamos a la virulencia del SarsCov-2.

\section{MATERIAL Y METODO}

Se realizó un estudio experimental y observacional, en el mes junio del año 2020, en las dependencias del servicio de dental del Hospital de La Florida de Santiago de Chile. La población de estudio corresponde a 10 pacientes sanos de Covid-19. Se utilizó tabla de criterios de inclusión y exclusión Tabla I.

Los pacientes fueron funcionarios del área de dental, voluntarios que cumplieron con los criterios de inclusión definido para este estudio. Se les entregó una carta de consentimiento informado (Anexo $\mathrm{N}^{\circ} 2$ ). El tamaño muestral ha sido definido por el Estadístico y para obtener 40 muestras, que coincidiendo con el número de muestras del estudio realizado por Bustamante et al.; para efectos comparativos. La muestra fue organizada aleatoriamente y los 10 voluntarios participaron en ambos box dentales, para disminuir la variable de tipo y cantidad de bacterias individuales que pudiesen influir en los resultados.

La unidad de estudio es la unidad dental o box dental. Son utilizadas 2 unidades dentales; la unidad de análisis el sillón dental, con el paciente, el dentista y su entorno inmediato (radio de 1,10 metros). Y un box de control ambiental, sin pacientes, ubicado en el mismo pasillo del box en estudio. Fue incluido en cada box: un profesional dentista, un asistente dental y un paciente. El estudio experimental se realiza luego de un fin de semana, donde se hizo un lavado y limpieza terminal de los box. Los box no presentan ventanas, ni ventilación y poseen aire acondicionado portátil, en los que se fijó una temperatura de $19{ }^{\circ} \mathrm{C}$ para ambos box.

Para determinar la presencia de bacterias en los aerosoles, se usaron placas de cultivo desechables con medio agar sangre, el cual fue elegido por sus características no selectivas y su habilidad de promover el crecimiento de muchos microorganismos.

La cúpula de acrílico utilizada, fue un diseño de PROYECTO71 LTDA, especialmente realizado para este estudio experimental. De tamaño $65 \times 45 \times 40$, cuenta con tres agujeros: dos laterales, uno para el dentista y la entrada la turbina, el otro para el técnico dental, y uno posterior para el dentista y el espejo de examinación (Fig.1).

Se tomaron en 2 grupos lo cultivos, uno control y otro grupo prueba. Además, se incluyó una placa de control ambiente. Estas placas se instalaron en el box 
VEnEGAS, A. M. C.; ROJAS, G. C. P.; CATALDO, S. Y. A.; JIMÉNEZ, G. P. F.; ARQUÉS, V. V. I. \& MARTINEZ, B. Contaminación bacteriana del aerosol dental con y sin uso de una cúpula de acrílico en un paciente en pandemia COVID-19. Int. J. Odontostomat., 15(1):14-22, 2021.

Tabla I. Criterios de inclusión y exclusión en el estudio de contaminación bacteriana del aerosol dental con y sin uso de una cúpula de acrílico.

\begin{tabular}{ll}
\hline \multicolumn{1}{c}{ Criterios de Inclusión } & \multicolumn{1}{c}{ Criterios de Exclusión } \\
\hline Funcionarios del Hospital de La Florida & No funcionario del Hospital de La Florida \\
& Con síntomas de covid-19 los últimos 14 días \\
Sin síntomas de covid-19 & Ha tenido contacto con algún paciente covid-19+ \\
Sin patologías de base & Con patología de base \\
Sin Fiebre & Con fiebre \\
Asintomático general & Embarazadas \\
Asintomático dental & Portador de prótesis removib les \\
& Portador de aparatos fijos de ortodoncia \\
\hline
\end{tabular}

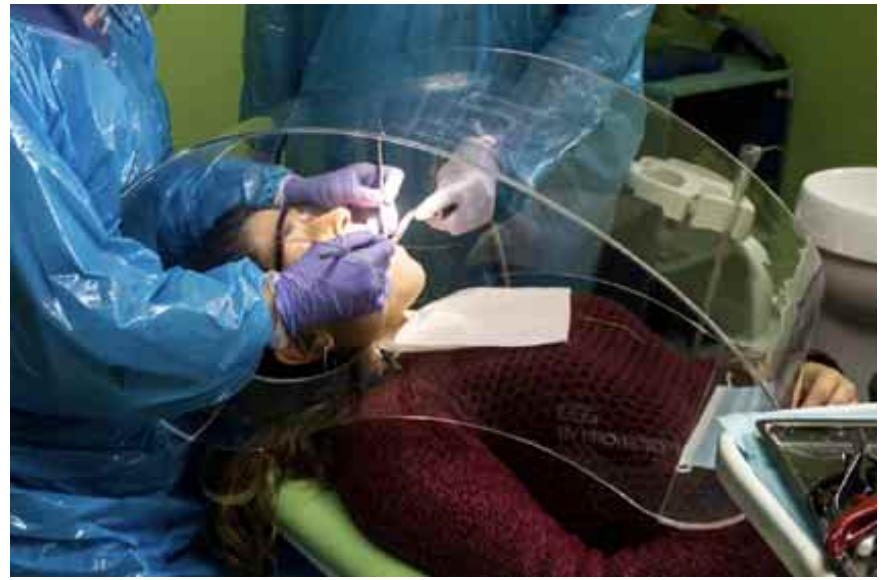

Fig. 1. Cúpula de acrílico utilizada para I parte experimental.

del grupo control, grupo prueba y en un Box desocupado; la placa fue puesta en el área limpia, correspondiente al mesón detrás de cada unidad dental, a 2 metros de la fuente de exposición del aerosol. Estas placas ambientales se destaparon al inicio de la actividad experimental 8:30 am, hasta la finalización, a las 12:30 pm del mismo día.

Los cultivos control y prueba se tomaron utilizando 20 placas, dos por cada paciente, atendidos sin Cúpula de acrílico, en un Box dental, Grupo Control y los mismos pacientes atendidos Con Cúpula de acrílico, en un Box dental, Grupo Prueba. Todo se realiza en la jornada de la mañana.

El protocolo de atención está basado en el "Protocolo de atención de pacientes en pandemia covid-19 del Hospital de La Florida" que tiene por objetivo disminuir los riesgos de contagio de COVID-19

Los cultivos se tomaron una vez instalado el paciente en la unidad dental, se posicionaron las placas: una en la pechera del paciente, aproximadamente a 20 $\mathrm{cm}$ de la fuente de emisión de aerosoles y la otra en la parte superior de la máscara facial del dentista, adosada por cinta de doble contacto, aproximadamente a $30 \mathrm{~cm}$ de la fuente de emisión de aerosoles (Fig. 2).

En todos los casos, los dos operadores realizaron acciones de simulación de trabajo de operatoria, eso quiere decir, colocar la turbina de alta velocidad en la cavidad oral zona mandibular, funcionando, sin aislamiento absoluto. Las placas se encontraban cerradas al momento de ubicarlas en los sitios de análisis, y se abrieron al comenzar

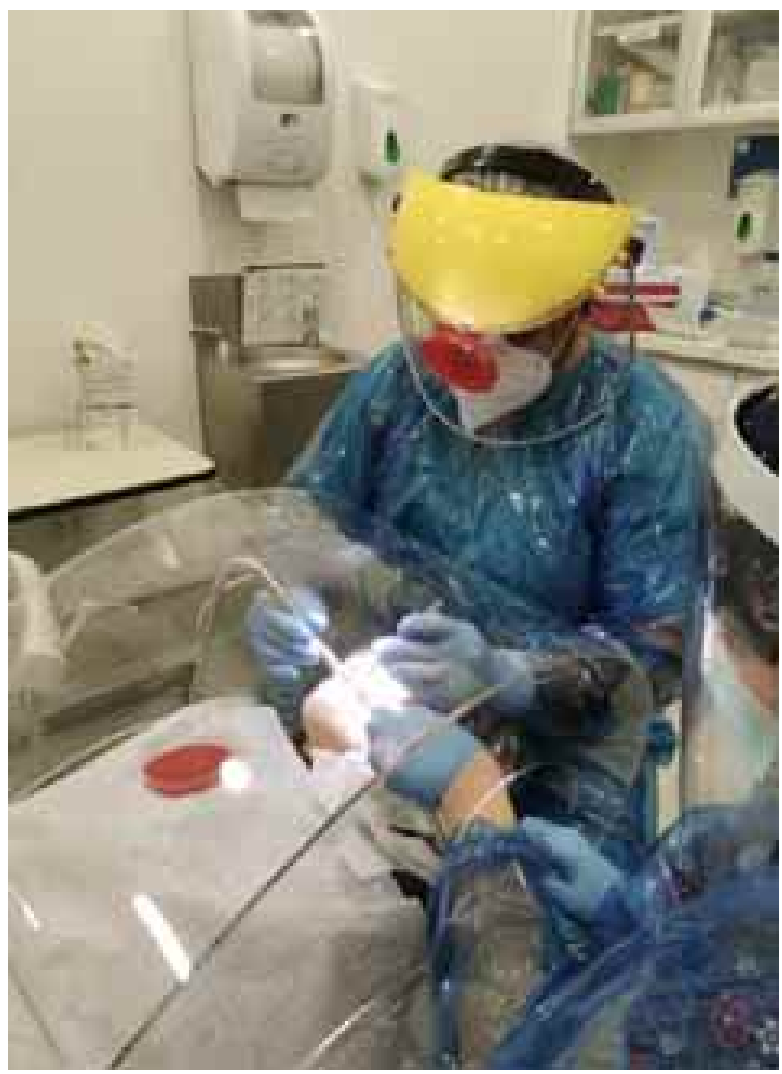

Fig. 2. Posicionamiento de las placas de Agar en Box con cúpula de Acrílico. 
VENEGAS, A. M. C.; ROJAS, G. C. P.; CATALDO, S. Y. A.; JIMÉNEZ, G. P. F.; ARQUÉS, V. V. I. \& MARTINEZ, B. Contaminación bacteriana del aerosol dental con y sin uso de una cúpula de acrílico en un paciente en pandemia COVID-19. Int. J. Odontostomat., 15(1):14-22, 2021.

el uso de la turbina, permaneciendo expuestas por 10 minutos contados con cronómetro, durante los cuales la turbina funcionó a intervalos intermitentes a su máxima potencia.

Posteriormente, las placas se sellaron, rotularon y enviaron al laboratorio de microbiología del hospital de la florida, a temperatura ambiente, para ser incubadas por $48 \mathrm{~h}$ en total a $37^{\circ} \mathrm{C}$; $24 \mathrm{~h}$ en atmósfera normal y 24 horas en atmósfera $\mathrm{CO}_{2}$, al cabo de este tiempo realizar recuento de UFC.

En todos los casos, se realizó el recuento de Unidades Formadoras de Colonias (UFC) de las placas incubadas, en el Laboratorio, por tres operadores independientes, previamente calibrados y luego del recuento de los tres se sacó un promedio por placa. Se realizó un análisis cuantitativo de las placas bajo estudio, posteriormente se analizaron los datos, a través, de tablas estadísticas, con el sofware Stat v 16.1.

\section{PROTOCOLO DE ATENCIÓN DE PACIENTES EN LA UNI- DAD DENTAL DEL HOSPITAL DE LA FLORIDA, JUNIO 2020, EN PANDEMIA.}

Al momento de acudir a la atención dental, el paciente deberá realizar el lavado de manos con agua y jabón en el baño. Luego, a través de la ventanilla de recepción, se le realizarán nuevamente las preguntas del triaje realizadas previamente por vía telefónica, y a modo de declaración jurada firmará un consentimiento escrito. Posteriormente, antes de ingresar al box, deberá seguir las siguientes indicaciones:

- Acudir solo.

- Se le tomará la temperatura antes de su ingreso al box dental.

- Retirarse pulseras, reloj, aros, collares.

- El uso de mascarilla es obligatorio.

- Antes de entrar al servicio dental, el paciente deberá limpiar su calzado en un tapete embebido en una solución de hipoclorito o amonio cuaternario de quinta generación.

- Se le pedirá nuevamente que se lave las manos con agua y jabón, o alcohol gel, antes de ingresar al box.

\section{Para el Dentista y la asistente:}

- Realizar siempre la higiene de manos con agua y jabón, antes y después de cada atención.

- Los EPP deben ser utilizados por el dentista, asistente, al momento de iniciar la atención dental.

- Previo al uso del EPP, el operador se retirará aros, argollas, reloj, colgantes u otros objetos que puedan entorpecer las distintas etapas de colocación y uso de las medidas de protección. Deberá asegurar el cabello de modo de evitar que se desplace sobre su rostro.

- Todo el equipo de salud deberá usar trajes clínicos y zapatos cerrados, distintos a la vestimenta de circulación fuera de los establecimientos de salud. EI EPP debe usarse sobre el traje clínico.

- Toda persona que se encuentre dentro del box dental, durante la atención del paciente, no podrá utilizar su celular ni ningún dispositivo electrónico.

- Colocarse el EPP según el tipo de atención a realizar (con o sin generación de aerosoles). En todos los casos debe contemplar el uso de mascarilla quirúrgica, pantalla facial, protectores oculares, cofia, guantes desechables y cubre calzado. En los casos en que se utilice instrumental rotatorio, el equipo necesario para atención de pacientes deberá incluir, además de lo anteriormente mencionado, pechera impermeable, y mascarilla N95.

- No dejar a la vista ni sobre la mesa el material que no se vaya a utilizar.

- Colocar film plástico sobre aquellas superficies con mayor contacto durante la práctica (botones del equipo, foco del sillón dental, bandeja del sillón dental, etc.), el cual deberá ser cambiado entre pacientes.

- Se recomienda trabajar a cuatro manos para evitar el riesgo de contaminación cruzada y optimizar el tiempo de trabajo.

- Se le pide al paciente que vuelva a lavar sus manos con alcohol gel o jabón, y que luego no toque nada.

- Se recomienda que el paciente realice un enjuague bucal con un colutorio de povidona yodada al $0,2 \%$ (povidona al $10 \%$, diluir 1 parte en 2 de agua) o de peróxido de hidrogeno al $1 \%$ (1 parte de $\mathrm{H}_{2} \mathrm{O}_{2}$ de 10 volúmenes diluida en 2 partes de agua) durante 30 segundos con el objeto de disminuir la carga viral. Este paso no fue se realizado para tener las bacterias en el cultivo.

- Se recomienda el uso de aspiración en alta potencia y cubrir con funda descartable la manguera del aspirador.

- Evitar el uso de la jeringa triple (agua y aire). Preferentemente secar con gasa. En caso usar jeringa triple ante una situación de urgencia; utilizar funda descartable en la manguera de la misma.

\section{Limpieza y desinfección del box dental posterior a la atención del paciente}

Posterior a la atención del paciente, y previo a la atención del siguiente, se debe realizar aseo terminal en cada box.

- Todo el instrumental será llevado al área de desinfección y esterilización, portando siempre los EPP.

- Se retiran los elementos protectores del mobiliario y se desechan en un contenedor especial para desechos biológicos.

- Se procederá a realizar una minuciosa limpieza y desinfección de todas las superficies que pudiesen estar en contacto con el aerosol producido durante la atención; esto se realizará con una toalla de papel o elemento descartable embebido en una solución de hipoclorito de sodio al $0,1 \%$ o amonio cuaternario de quinta generación. Dejar actuar el producto unos minutos. 
- Se procederá a la desinfección del material de protección ocular y al cuidadoso descarte del EPP desechable.

- Todas las zonas comunes serán sometidas a limpieza y desinfección.

- La cápsula de acrílico será retirada una vez termine de funcionar la turbina, se le rociará agua jabonosa y se lavará con abundante agua, se secará y se rociará con alcohol en spray para desinfectarla y ser utilizada por el siguiente paciente.

\section{RESULTADOS}

Fueron adecuadamente procesadas 43 muestras de cultivos, 20 de las placas control, 20 de prueba y 3 placas de ambiente. Todas las placas fueron positivas para crecimiento bacteriano. En las placas puestas en la pechera del paciente, se encontraron 191,46 promedio y 141,0 desviación estándar de UFC en el box sin cúpula y 248,23 promedio y 158,43 desviación estándar en el box con cúpula, (Tabla III). Datos que no tenían distribución normal, por lo que se realizó el test del signo de Wilcoxon, observándose que no había una diferencia significativa entre ambos grupos obteniendo un $p=0,7539$.

Tabla II. Unidades Formadoras de Colonias (UFC), por paciente atendido en un box con y sin cúpula, de las placas de cultivo puestas en la máscara facial.

\begin{tabular}{ccc}
\hline$N^{\circ}$ MUESTRAS & $\begin{array}{c}\text { UFC BOX SIN } \\
\text { CÚPULA MÁSCARA } \\
\text { FACIAL }\end{array}$ & $\begin{array}{c}\text { UFC BOX CON } \\
\text { CÚPULA MÁSCARA } \\
\text { FACIAL }\end{array}$ \\
\hline V1 & 7 & 1,66 \\
V2 & 3,33 & 1 \\
V3 & 7 & 1 \\
V4 & 32,33 & 2 \\
V5 & 16 & 6,66 \\
V6 & 6 & 2,33 \\
V7 & 3 & 22 \\
V8 & 1 & 1 \\
V9 & 3,33 & 0,33 \\
V10 & 2 & 1 \\
\hline PROMEDIO & 8,1 & 3.9 \\
\hline DESVIACIÓN & 9,5 & 6,6 \\
STANDAR & & \\
\hline
\end{tabular}

En las placas puestas en la máscara facial, se encontraron 8,1 promedio y 9,5 desviación estándar de UFC, en el box sin cúpula, y 3,9 promedio y 6,6 desviación estándar de UFC en el box con cúpula, datos que no tenían distribución normal, por lo que se realizó el test del signo de Wilcoxon observándose diferencias significativas $p=0,0391$ (Tabla III).
Tabla III. Unidades Formadoras de Colonias (UFC), por paciente atendido en un Box con y sin cúpula, de las placas de cultivo puestas en la pechera del paciente.

\begin{tabular}{|c|c|c|}
\hline$N^{\circ}$ MUESTRAS & $\begin{array}{c}\text { UFC BOX SIN } \\
\text { CÚPULA PECHERA }\end{array}$ & $\begin{array}{c}\text { UFC BOX CON } \\
\text { CÚPULA PECHERA }\end{array}$ \\
\hline V1 & 151,33 & 277,66 \\
\hline V2 & 96,66 & 191 \\
\hline V3 & 175 & 80 \\
\hline V4 & 451,66 & 433,66 \\
\hline V5 & 285,66 & 328,66 \\
\hline V6 & 206,66 & 158,33 \\
\hline V7 & 37 & 500,66 \\
\hline V8 & 379 & 57,33 \\
\hline V9 & 84 & 375 \\
\hline V10 & 47,66 & 80 \\
\hline PROMEDIO & 191,46 & 248,23 \\
\hline DESVIACIÓN & \multirow{2}{*}{141} & \multirow{2}{*}{158,43} \\
\hline STANDAR & & \\
\hline
\end{tabular}

En el box Sin Cúpula, el promedio de las Unidades Formadoras de Colonias fue de 200, y Con Cúpula fue de 252 (Tablas IV y V). Todas las placas ambientales fueron positivas para crecimiento bacteriano. Las placas puestas en el área limpia del box, se encontraron 34,66 UFC en promedio, 28,33 UFC en el box con cúpula, 29 UFC en el box Control sin atención, y 46,66 UFC en el box sin Cúpula.

Tabla IV. Promedio de Unidades Formadoras de Colonias (UFC) de los sujetos box Sin Cúpula.

\begin{tabular}{cccc}
\hline & UFC S/C & UFC S/C & UFC TOTAL \\
$\mathrm{N}^{\circ}$ MUESTRAS & MASCARA FACIAL & PECHERA & \\
\hline V1 & 7 & 151 & 158,33 \\
V2 & 3 & 97 & 100 \\
V3 & 7 & 175 & 182 \\
V4 & 32,33 & 452 & 483,99 \\
V5 & 16 & 286 & 301,66 \\
V6 & 6 & 207 & 212,66 \\
V7 & 3 & 37 & 40 \\
V8 & 1 & 379 & 380 \\
V9 & 3 & 84 & 87 \\
V10 & 2 & 48 & 49,66 \\
Promedio & 8 & 191 & 200 \\
\hline
\end{tabular}

Tabla V. Promedio de Unidades Formadoras de Colonias (UFC) de los sujetos box Con Cúpula

\begin{tabular}{cccc}
\hline$N^{\circ}$ MUESTRAS & $\begin{array}{c}\text { UFC C/C } \\
\text { MASCARA } \\
\text { FACIAL }\end{array}$ & $\begin{array}{c}\text { UFC C/C } \\
\text { PECHERA }\end{array}$ & UFC TOTAL \\
\hline V1 & 2 & 278 & 279 \\
V2 & 1 & 191 & 192 \\
V3 & 1 & 80 & 81 \\
V4 & 2 & 434 & 435,66 \\
V5 & 7 & 329 & 335 \\
V6 & 2 & 158 & 161 \\
V7 & 22 & 501 & 522,66 \\
V8 & 1 & 57 & 58,33 \\
V9 & 0,33 & 375 & 375,33 \\
V10 & 1 & 80 & 81 \\
\hline Promedio & 38.99 & 248.23 & 252 \\
\hline
\end{tabular}


VENEGAS, A. M. C.; ROJAS, G. C. P.; CATALDO, S. Y. A.; JIMÉNEZ, G. P. F.; ARQUÉS, V. V. I. \& MARTINEZ, B. Contaminación bacteriana del aerosol dental con y sin uso de una cúpula de acrílico en un paciente en pandemia COVID-19. Int. J. Odontostomat., 15(1):14-22, 2021

\section{DISCUSIÓN}

De acuerdo a los resultados obtenidos en esta investigación podemos señalar que, existe una gran cantidad de microorganismos presentes en los aerosoles generados durante los procedimientos odontológicos, (aún cuando éstos fueron simulados), en los que se usa turbina, y que constituirían un riesgo de infección para el operador, lo que está en directa concordancia con estudios realizados por Bustamante et al., Shpuntoff \& Shpuntoff, Pankhurst (1993), Prieto \& Maestre (2003), Santiago et al. y Sanclement et al. (2005)

El número promedio de UFC encontradas en este estudio (pechera más máscara facial), en el box sin uso de Cúpula, fue de 200 UFC, lo que es casi cuatro veces más que lo encontrado por Bustamante et al., de 58,8 UFC. Esto se puede explicar porque en este estudio no se utilizó aislamiento absoluto en el momento del procedimiento Odontológico, como lo hicieron Bustamante et al.. Mientras que, en el box con cúpula, el promedio de bacterias fue mayor, 252 UFC, lo que se puede atribuir a que las bacterias encontradas en la pechera del paciente se concentran más dentro de la cúpula, no diseminándose por el ambiente del box, ya que la cúpula representa una barrera física, no elimina ni succiona las partículas de aerosol, lo que sí produce es una disminución de la cantidad de contaminación ambiental. Esto se explica y demuestra con el valor de 28,3 UFC ambientales, encontradas en el área limpia (a $2 \mathrm{mt}$ de la emisión de aerosol), cuyo valor coincide con las 29 UFC del box ambiental control, sin atención de pacientes. Ambos muestran una diferencia de 18,3 UFC, con el box sin cúpula $(46,66$ UFC) un tercio más de bacterias. Estos resultados, 29 UFC, son comparables a los 39 UFC que se consideran como "aceptables", en lo que se refiere a contaminación bacteriana.

Existe una diferencia marcada entre la cantidad de microorganismos encontrados en los aerosoles recolectados desde la pechera del paciente y la máscara facial del operador, siendo mayor la cantidad de microorganismos hacia la pechera del paciente, resultados que coinciden con Bustamante et al. y Pankhurst.

Si bien no hay una diferencia estadísticamente significativa en la cantidad de bacterias encontradas en la pechera del paciente, entre el box con cúpula y sin cúpula, sí se muestra una tendencia de mayor cantidad de bacterias en la pechera del box con cúpula, lo cual se podría explicar por el confinamiento mayor de las bacterias dentro de la cúpula, y tal como fue explicado anteriormente, éstas no se diseminan hacia el medio ambiente del box.

Por otro lado, las máscaras faciales de ambos box fueron contaminadas con bacterias, con una diferencia significativa mayor en el box de atención sin cúpula, con lo cual se confirma la protección de la cúpula de acrílico hacia el operador.

El uso de la cúpula de acrílico para la atención de pacientes en los procedimientos dentales, ha demostrado marcar una diferencia significativa, en la contaminación de bacterias para el operador, y por ende el ambiente. Es interesante observar que, pese a que no se dió tiempo de ventilación entre pacientes, ni tampoco existió ésta, ya que los Box del Hospital de La Florida son cerrados, sin extractores de aire, las muestras de la máscara facial no se fueron contaminando de manera acumulativa, por el posible aerosol que quedara de los tratamientos previos y que fuera precipitando en el Box donde no se utilizó cúpula de acrílico como contención. Esto demuestra que la cúpula de acrílico evita que se diseminen los aerosoles, siendo una protección importante para el operador, el asistente y el box.

Como se mencionó anteriormente, no hay diferencia importante en la cantidad de UFC de la pechera del paciente con o sin cúpula, sí la importancia es que al quedar capturadas éstas en el interior de la cúpula, el aseo prolijo de desinfección terminal en la cúpula, entre pacientes, es básico.

En cuanto al uso de aislamiento en los procedimientos odontológicos, al no utilizarlos en este estudio, y al comprobar que los aerosoles constituyen una fuente importante de emisión de microorganismos, se hace imprescindible cumplir con todas las normas de bioseguridad que protegen tanto al operador como al paciente (Toroglu et al., 2001; Harrel \& Molinari, 2004 y Bustamante et al.). Y junto a ello, considerar el uso de la Cúpula de Acrílico para esta protección, ya que constituye una alternativa a procedimientos que generan aerosol 
en donde el aislamiento absoluto con goma dique dificulta su ejecución y extiende los tiempos operatorios, como es el caso de detartrajes supra y subgingivales, mediante el uso de ultrasonido.

Este estudio sirve para entender la contaminación de las bacterias en un procedimiento dental, su cantidad y se puede extrapolar a lo que sucedería con los virus, los cuales son más livianos, pero también más lábiles en el ambiente. Se requieren más estudios acerca de este tema que involucren nuevas variables acerca del control de infecciones virales la acción de los aerosoles generados en odontología y su contaminación en las superficies de manera más específica con el Sars-cov-2.

Como conclusión la cúpula evita la diseminación de los aerosoles, protege al operador y proporciona seguridad en la atención del paciente en tiempo de pandemia de COVID-19

\section{AGRADECIMIENTOS}

Quiero agradecer en primer lugar a mi familia, Juan Pablo, Benjamin, Joaquin, por el apoyo y motivación que me han dado en esta bella labor de hacer investigación. Agradecer a mi Jefatura, Dra. Ximena Contreras que desde siempre confió en mi criterio y apoyó para que pudiera desarrollar esta investigación. A Dra. Paula Jiménez, jefa de dental que me dio su aprobación y apoyo en recurso humano y físico para llevar a cabo la parte experimental. A la Dra. Lorean Castillo jefa de Laboratorio del HLF y sobre todo a Daniela Ramirez Fuentealba, Tecnóloga Médica del Laboratorio del HLF, que nos ayudó en el procesamiento de las muestras y su apoyo logístico. Agradecimientos al Dr. Benjamín Martínez, Odontólogo- Patólogo y Estadístico, quien me guió y apoyó en la parte numérica y evidencia estadística. Agradecer a mi madre querida, Victoria Arqués Vergara, Enfermera, quien con su potencial, rigurosidad y amor ha sido la energía científica que me ayuda a ver con otros ojos los detalles y me motiva a resolverlos. Gracias al equipo de investigadores: Yuri Cataldo, Carolina Rojas, Paula Jimenez, por trabajar en conjunto para el desarrollo de esta tarea. A todo el equipo de dental del HLF por su gran vocación de servicio y apoyo en todo y a las enfermeras de IAAS del HLF, Rosita y Marcela, por la orientación en el trabajo con microorganismos y su limpieza y desinfección de la cúpula dental.
VENEGAS, A. M. C.; ROJAS, G. C. P.; CATALDO, S. Y. A.; JIMÉNEZ, G. P. F.; ARQUÉS, V. V. I. \& MARTINEZ, B. Bacterial contamination of dental aerosol with and withou use of an acrylic dome in a patient in COVID-19 pandemic. Int. J. Odontostomat., 15(1):14-22, 2021.

ABSTRACT: In the current PANDEMIC for COVID19 , the clinical world has been forced to reinforce the use of protection in healthcare, due to the high degree of contagion and virulence of this virus. In dentistry, due to the production of aerosols, clinical care has been suspended to prevent infection. The objective of this research is to determine the amount of bacterial contamination, generated by the use of high-speed micromotor aerosol, carried out by dentists at the Hospital de La Florida, Santiago, Chile. The study included 10 patients per box, with 2 samples per patient, in total 40 culture plates, 20 Control, 20 Test and 3 Environmental. The culture medium was kept for 10 minutes, located in the front of the operator and the patient's chest. Simulation of the operation with a turbine was performed, without absolute isolation, with and without the use of an acrylic dome, placed on a healthy patient. The samples were analyzed macroscopically, incubated at $37^{\circ} \mathrm{C}$ in an atmosphere of oxygen for 24 hours and Carbon dioxide after 48 hours. 43 plates were positive, noting a non-significant difference $(p=0.753)$ between the two groups in the bib samples, with an average difference of 56.76 CFU. In the plates of the operator's forehead, an average of $8.1 \mathrm{CFU}$ in the box without dome and 3.9 CFU in the box with dome, finding a statistically significant difference $(p=0.0391)$. The environmental plates 28.33 UFC in the Box with the dome, 29 UFC in the Control Box and the Box without dome 46.66 UFC. When verifying that the acrylic dome effectively contains aerosols, it should be used as a biosafety standard to protect both dental equipment and patients in times of pandemic against COVID-19.

KEY WORDS: aerosols, covid-19, pandemic, humans, hospitals, dentists.

\section{REFERENCIAS BIBLIOGRÁFICAS}

Backer, J. A.; Klinkenberg, D. \& Wallinga, J. Incubation period of 2019 novel coronavirus (2019-nCoV) infections among travellers from Wuhan, China, 20-28 January 2020. Euro Surveill., 25(5):2000062, 2020.

Bustamante, A. M. F.; Herrera, M. J.; Ferreira, A. R. \& Riquelme, S. D. Analysis of bacterial contamination produced by aerosols in dental clinic environments. Int. J. Odontostomat., 8(1):99-105, 2014.

Chen, N.; Zhou, M.; Dong, X.; Qu, J.; Gong, F.; Han, Y.; Qiu, Y.; Wang, J.; Liu, Y.; Wei, Y.; et al. Epidemiological and clinical characteristics of 99 cases of 2019 novel coronavirus pneumonia in Wuhan, China: a descriptive study. Lancet, 395(10223):50713, 2020.

Dreyer, A. G. \& Hauman, C. H. Bacterial contamination of dental handpieces. SADJ, 56(11):510-2, 2001. 
VENEGAS, A. M. C.; ROJAS, G. C. P.; CATALDO, S. Y. A.; JIMÉNEZ, G. P. F.; ARQUÉS, V. V. I. \& MARTINEZ, B. Contaminación bacteriana del aerosol dental con y sin uso de una cúpula de acrílico en un paciente en pandemia COVID-19. Int. J. Odontostomat., 15(1):14-22, 2021.

Dutil, S.; Meriaux, A.; de Latremoille, M. C.; Lazure, L.; Barbeau, J. \& Duchaine, C. Measurement of airborne bacteria and endotoxin generated during dental cleaning. J. Occup. Environ. Hyg., 6(2):121-30, 2009.

Guan, W. J.; Ni, Z. Y.; Hu, Y.; Liang, W. H.; Ou, C. Q.; He, J. X.; Liu, L.; Shan, H.; Lei, C. L.; Hui, D. S. C.; et al. Clinical Characteristics of Coronavirus Disease 2019 in China. N. Engl. J. Med., 382(18):1708-20, 2020.

Harrel, S. K. \& Molinari, J. Aerosols and splatter in dentistry: a brief review of the literature and infection control implications. J. Am. Dent. Assoc., 135(4):429-37, 2004.

Hauman, C. H. Cross-infection risks associated with high-speed dental handpieces. J. Dent. Assoc. S. Afr., 48(7):389-91, 1993.

Johns Hopkins University of Medicine. Coronavirus Resource Center. COVID-19 Dashboard by the Center for Systems Science and Engineering (CSSE). Baltimore, Johns Hopkins University of Medicine, 2020. Disponible en: https://coronavirus.jhu.edu/ map.html

Ministerio de Salud (MINSAL). Cifras Oficiales COVID-19. Santiago de Chile, Ministerio de Salud, Gobierno de Chile, 2020. Disponible en: https://www.gob.cl/coronavirus/cifrasoficiales/

Pankhurst, C. L. Risk assessment of dental unit waterline contamination. Prim. Dent. Care, 10(1):5-10, 2003.

Prieto, J. \& Maestre, J. R. Tratamiento de las Infecciones de Etiología Mixta. En: Bascones, A. \& Perea, E. J. (Eds). Infecciones Orofaciales. Madrid, Dentisnet, 2003. pp.245-56.

Sanclement, J. A.; Webster, P.; Thomas, J. \& Ramadan, H. H. Bacterial biofilms in surgical specimens of patients with chronic rhinosinusitis. Laryngoscope, 115(4):578-82, 2005.

Santiago, J. I.; Huntington, M. K.; Johnston, A. M.; Quinn, R. S. \& Williams, J. F. Microbial contamination of dental unit waterlines: short- and long-term effects of flushing. Gen. Dent., 42(6):52835, 1994

Shpuntoff, H. \& Shpuntoff, R. L. High-speed dental handpieces and spread of airborne infections. N. Y. State Dent. J., 59(1):21-3, 1993.

Subsecretaria de Salud Pública. Orientaciones para Atención Odontológica en Fase IV COVID-19. Santiago de Chile, Subsecretaria de Salud Pública, División de Prevención y Control de Enfermedades, Departamento Salud Bucal, Ministerio de Salud, Gobierno de Chile, 2020. Disponible en: https:// diprece.minsal.cl/documentos-de-apoyo-covid-19/

Toroglu, M. S.; Haytac, M. C. \& Köksal, F. Evaluation of aerosol contamination during debonding procedures. Angle Orthod., 71(4):299-306, 2001

Veena, H. R.; Mahantesha, S.; Joseph, P. A.; Patil, S. R. \& Patil, S. $\mathrm{H}$. Dissemination of aerosol and splatter during ultrasonic scaling: a pilot study. J. Infect. Public Health, 8(3):260-5, 2015.

Yi, Y.; Lagniton, P. N. P.; Ye, S.; Li, E. \& Xu, R. H. COVID-19: what has been learned and to be learned about the novel coronavirus disease. Int. J. Biol. Sci., 16(10):1753-66, 2020.

Zou, L.; Ruan, F.; Huang, M.; Liang, L.; Huang, H.; Hong, Z.; Yu, J.; Kang, M.; Song, Y.; Xia, J.; et al. SARS-CoV-2 Viral Load in Upper Respiratory Specimens of Infected Patients. N. Engl. J. Med., 382(12):1177-9, 2020.
Dirección para correspondencia:

Dra. María Cecilia Venegas Arqués

Clínica Agusto Leguia Sur 79 of. 305

Las Condes

Santiago

CHILE

Email: dra.mceciliavenegas@gmail.com 